\title{
Escherichia coli enteroagregativa como agente provocador de diarreia persistente: modelo experimental utilizando microscopia óptica de luz
}

\author{
Enteroaggregative Escherichia coli as a cause of persistent diarrhea: an experimental model using light \\ microscopy
}

Jacy Alves B. de Andrade1, Edna Freymüller Haapalainen², Ulysses Fagundes-Neto ${ }^{3}$

\section{RESUMO}

Objetivo: Avaliar interações de amostras de Escherichia coli enteroagregativa com tecido intestinal humano, a fim de documentar potenciais alterações em diferentes regiões do trato digestivo.

Métodos: Amostras de Escherichia coli enteroagregativa isoladas das fezes de crianças com diarreia persistente e a amostra protótipo 042 , isolada de uma criança com diarreia em Lima, no Peru (controle positivo), foram analisadas por microscopia óptica de luz após semeadura em cultura de orgão in vitro de fragmentos de mucosa ileal e colônica. Foram analisadas as interações entre as diferentes cepas de Escherichia coli enteroagregativa e as mucosas ileal e colônica.

Resultados: A análise por microscopia óptica de luz indicou associação destes micro-organismos com o epitélio, provocando alterações. As cepas estudadas aderiram a ambas as regiões avaliadas (intestino delgado distal e grosso) e causaram alterações, especialmente naquelas áreas onde interagiram diretamente com o epitélio. No íleo, algumas regiões mostraram internalização secundária.

Conclusões: Esses agentes podem causar diarreia persistente por meio de alterações no intestino delgado, no qual ocorrem as funções digestivo-absortivas. As lesões inflamatórias descritas na mucosa colônica poderiam explicar a colite mostrada em algumas crianças infectadas por Escherichia coli enteroagregativa.

Palavras-chave: Escherichia coli agregativa; diarreia persistente; microscopia.

\section{ABSTRACT}

Objective: To examine the interactions of Enteroaggregative Escherichia coli strains with small and large intestinal mucosa, in order to detect potential alterations in both regions of the digestive tract.

Methods: Enteroaggregative Escherichia coli strains, isolated from stools of infants with persistent diarrhea and the prototype strain $042(\mathrm{O} 44: \mathrm{H} 18)$, isolated from a child with diarrhea in Lima, Peru (positive control), were analised by light microscopy after in vitro organ culture assay of ileal and colonic mucosa. The interactions between the different enteroaggregative Escherichia coli strains and the ileal and colonic mucosa were analysed.

Results: Light microscopy analysis suggested an association of enteroaggregative Escherichia coli strains with the epithelium, inducing alterations. These bacteria adhered to both small and large bowel mucosa. The enteroaggregative Escherichia coli strains induced alterations in those areas where they were directly interacting with the
Instituição: Universidade Federal de São Paulo (Unifesp), São Paulo, SP, Brasil

'Doutora pelo Programa de Pediatria e Ciências Aplicadas à Pediatria da Unifesp, São Paulo, SP, Brasil

2Livre-docente pela Unifesp; Professora Associada do Centro de Microscopia Eletrônica da Unifesp, São Paulo, SP, Brasil

${ }^{3}$ Livre-docente pela Unifesp; Professor Titular da Disciplina de Gastroenterologia Pediátrica da Unifesp, São Paulo, SP, Brasil
Endereço para correspondência

Ulysses Fagundes-Neto

Avenida Conselheiro Rodrigues Alves, 1.239 - Vila Mariana

CEP 04014-010 - São Paulo/SP

E-mail: ufagundesneto@uol.com.br

Fonte financiadora do projeto: Conselho Nacional de Desenvolvimento Científico e Tecnológico (processo no 306615/2006-1 Modalidade Produtividade em Pesquisa)

Conflito de interesse: nada a declarar

Recebido em: 12/11/2009

Aprovado em: 08/06/2010 
epithelium. In the ileum, some areas showed a secondary internalization.

Conclusions: The enteroaggregative Escherichia coli strains could cause persistent diarrhea inducing alterations in the small intestinal structures, where the digestive-absorptive functions take place. Inflammatory lesions observed in colons could justify the colitis described in some children infected by enteroaggregative Escherichia coli.

Key-words: enteroaggregative Escherichia coli; persistent diarrhea; microscopy.

\section{Introdução}

A doença diarreica continua sendo resposável por uma grande proporção de mortes em crianças menores de cinco anos ao redor do mundo $(20 \%)^{(1)}$. A diarreia persistente tem alto impacto nas taxas de morbidade e mortalidade nas populações pediátricas em países em desenvolvimento, e mais de $50 \%$ das mortes nestes países estão associadas a estes episódios ${ }^{(2)}$.

As lesões encontradas no intestino delgado estão no cerne da fisiopatologia da diarreia persistente ${ }^{(3)}$, mas é necessário fazer uma distinção entre a enteropatia causada pela persistência da colonização bacteriana e a pós-infecciosa, que ocorre por falha ou por retardo na regeneração da mucosa intestinal ${ }^{(4)}$. Muitos trabalhos estão focados na caracterização do dano, identificando alterações nas capacidades absortivas, secretoras e reabsortivas de minerais, carboidratos, proteínas e gorduras provocadas pela cronificação da enteropatia ${ }^{(5)}$. As lesões descritas em crianças com diarreia persistente parecem ser causadas por vários fatores, agindo em associação ou separadamente. Tais fatores acabam provocando um prolongamento da enteropatia e um retardo na recuperação da mucosa ${ }^{(3)}$. Os patógenos detectados na diarreia persistente nem sempre são os mesmos encontrados na fase aguda da doença, sugerindo que infecções secundárias possam ser um fator importante no prolongamento do episódio diarreico ${ }^{(6)}$. O retardo na reparação da mucosa parece ser o principal componente do processo e tudo indica que outros fatores também podem perpetuar o dano. Enteropatógenos provocam diarreia, lesando as vilosidades intestinais e secretando toxinas que atuam nos enterócitos. A recuperação do processo diarreico somente ocorrerá quando as células danificadas forem repostas. Anormalidades que resultam num retardo da regeneração epitelial são, portanto, responsáveis pelo prolongamento do processo diarreico ${ }^{(7)}$. Por outro lado, há descrições de que estes micro-organismos também podem colonizar a mucosa colônica, causando colite infecciosa associada à diarreia sanguinolenta ${ }^{(8)}$.

Alguns sorotipos de Escherichia coli, que demonstram diversas propriedades de aderência em culturas de tecidos, se revelam importantes patógenos intestinais. Por definição, Escherichia coli enteroagregativa (EAEC) é um grupo de bactérias que abrange sorogrupos de Escherichia coli, os quais aderem a linhagens celulares in vitro, tais como células HeLa e HEp-2, formando agregados bacterianos localizados na superfície celular e em regiões da lamínula livre de células, em arranjo semelhante a tijolos empilhados (aderência agregativa) $)^{(9)}$. A configuração em "pilha de tijolos" é considerada uma condição obrigatória para o padrão típico de aderência agregativa $(\mathrm{AA})^{(10)}$. A patogênese da EAEC é complexa e cepas de EAEC são muito heterogêneas ${ }^{(11)}$. Apesar de vários estudos enfatizarem a associação destas cepas com a mucosa colônica, alguns autores já mostraram sua capacidade de colonizar o intestino delgado ${ }^{(12)}$. Estudos realizados em humanos e em animais demonstram interação destes micro-organismos com epitélio jejunal, ileal e colônico ${ }^{(13,14)}$.

Vários fatores de virulência são identificados nesses agentes, mas a sua implicação clínica ainda não está totalmente estabelecida ${ }^{(15)}$. Portanto, estudos para avaliar a interação dessas bactérias com a mucosa intestinal são necessários. Este trabalho foi desenhado para avaliar a interação de três cepas de EAEC isoladas de crianças portadoras de diarreia persistente e documentar as potenciais alterações em diferentes regiões do trato digestivo (intestino delgado distal e intestino grosso), utilizando a microscopia de luz (ML) para definir seu papel na persistência do processo diarreico.

\section{Método}

As amostras de EAEC (cepas 071-1,101-1 e 171-1) utilizadas neste estudo foram isoladas das fezes de crianças menores de seis meses, portadoras de diarreia persistente (EAEC-CASOS). Como controle positivo, foi utilizada a cepa protótipo $042^{(10)}$, a qual possui efeito citopático nas regiões presentemente investigadas.

A identificação das EAEC foi realizada com base em seu padrão de adesão agregativo a células HeLa e HEp-2 e com o uso de sonda genética específica - AA, que detecta os genes associados à propriedade de causar adesão do tipo agregativa - pCVD 432 $2^{(16)}$. A identificação dos antígenos somático $(\mathrm{O})$ e flagelar $(\mathrm{H})$ foi realizada pelas técnicas de aglutinação padrão ${ }^{(17)}$. Cepas não-tipáveis foram definidas como NT. 
As cepas de EAEC empregadas neste estudo foram a cepa protótipo 042 (O44:H18) e as cepas 71-1 (ONT:H33), 101-1 (ONT:H10) e 171-1 (ONT:H1).

Os fragmentos intestinais humanos foram obtidos em cirurgias de ressecção intestinal, realizadas em pacientes pediátricos e também em colonoscopias de adultos. Em ambos os casos, foram selecionados tecidos de mucosa ileal e/ou de mucosa colônica com macroscopia normal. Os procedimentos de adesão foram realizados segundo as orientações descritas por Knutton, Lloyd e McNeish ${ }^{(18)}$, com algumas modificações. As biópsias foram transportadas para o laboratório após serem colocadas em meio de cultura de órgão modificado (MOCM), adaptado como a descrição de Embaye et a ${ }^{(19)}$, com NCTC-135 (SIGMA) com 2mM de L-glutamina (SIGMA), MTT8 (FLOW) e soro de recém-nascido bovino. Os fragmentos mantidos em MCOM foram colocados em paraformaldeído a $4 \%$ para processamento em ML. As cepas de EAEC foram testadas com três fragmentos intestinais para cada região avaliada.

Os fragmentos de biópsias foram colocados com as vilosidades voltadas para cima em papéis de filtro estéreis (AP20; Millipore), em uma placa de Petri (35 X 10mm; Corning). O nível de MCOM contendo $1 \%$ de D-manose foi ajustado de maneira que uma fina camada de meio de cultura cobrisse a superfície dos fragmentos intestinais. Após lavagem dos fragmentos intestinais testados com MCOMm, estes foram fixados, utilizando-se uma solução de paraformaldeído a $4 \%$ durante 24 horas. Realizou-se, então, desidratação sequencial com etanol a 70\%. Após isso, foi feita a pré-infiltração com uma mistura de etanol a $100 \%$ e glicolmetacrilato (GMA-resina Historesin) (LKB) em partes iguais por 12 horas à temperatura ambiente e, então, os fragmentos foram transferidos para a solução de infiltração GMA por 24 horas. Os fragmentos orientados com auxílio de um microscópio esteroscópico, de forma que as vilosidades intestinais ficassem voltadas para cima, foram incluídos, à temperatura ambiente, em uma mistura de resina Historesin e GMA, contida em moldes de silicone do kit Historesin. Depois, cortaram-se os blocos em micrótomo (SORVALL JB 4A) com navalha de vidro (EMS), numa espessura de $1,0 \square \mathrm{m}$. A seguir, os cortes foram corados pela solução de azul de toluidina a $1 \%$ por quatro minutos e depois em solução de fucsina por 30 segundos (toluidina-fucsina) para observação em ML, com aumentos de 100, 200, 400 e 1000X.

Este protocolo de estudo foi aprovado pelo Comitê de Ética da Escola Paulista de Medicina da Universidade Federal de São Paulo (Unifesp). Um termo de consentimento foi obtido dos pacientes adultos ou dos responsáveis por cada criança participante.

\section{Resultados}

A análise por ML dos fragmentos de cólon controle mostrou superfície celular preservada, com enterócitos em paliçada. As células caliciformes e a bordadura estriada mostraram-se intactas (Figuras 1A e 1B). A análise da mucosa colônica infectada com a cepa 042 revelou a presença de bactérias na luz intestinal e na camada de muco que recobre o epitélio (Figura 2). Bactérias apareceram em contato com a bordadura estriada (Figuras 2B e 2D). Focalmente, foram demontradas áreas de descolamento do epitélio (Figura 2A). Em várias regiões do tecido, ocorreu vacuolização citoplasmática na região basal dos enterócitos (Figuras 2C e 2D).

A mucosa colônica infectada com a cepa 171-1 mostrou bactérias agregadas em "pilha de tijolos" distante da superfície epitelial, em meio a células inflamatórias. No epitélio, grande quantidade de células caliciformes com áreas de lise,

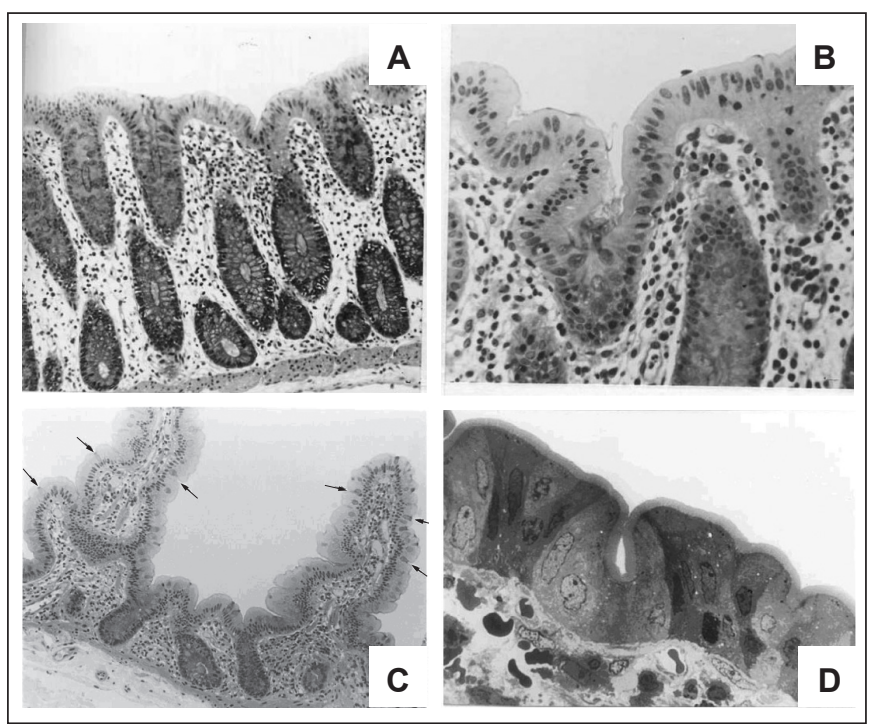

Figura 1 - Microscopia óptica de fragmentos de cólon e íleo controle. A (105X) e B (210X) - Mucosa do cólon preservada e caracterizada por células epiteliais cilíndricas com núcleo em posição basal e infiltrado inflamatório linfoplasmocitário na lâmina própria fisiológico; C (105X) - Mucosa ileal preservada evidenciando vilosidades digitiformes, células epiteliais cilíndricas com núcleo em posição basal, células caliciformes permeando o epitélio $(\downarrow)$ e infiltrado linfoplasmocitário fisiológico na lâmina própria. D (1050X) - Aumento maior evidenciando a borda estriada (microvilosidades) intacta e células epiteliais cilíndricas com núcleo em posição basal. 
destruição e extrusão celular foram observadas. Cortes de fragmentos de mucosa colônica mostraram a cepa 71-1 em agregados típicos, próximos ao epitélio, que encontrou-se, em algumas áreas, despregado do córion. Extrusão celular também foi documentada. A bordadura estriada pareceu intacta em muitas regiões, mas nos locais onde as bactérias encontraram-se aderidas, as microvilosidades mostraram-se alteradas.

A análise por ML dos fragmentos de íleo controle (Figuras $1 \mathrm{C}$ e $1 \mathrm{D})$ mostrou tecido intacto com arquitetura vilositária preservada, enterócitos em paliçada com células caliciformes em grande número, sem anormalidades aparentes. A borda em escova apresentou-se aparentemente intacta. Nos cortes controle, não foi observado muco, nem restos celulares na superfície epitelial.

A análise da mucosa ileal infectada com a cepa 042 revelou vilosidades com áreas de arrancamento do epitélio, o qual

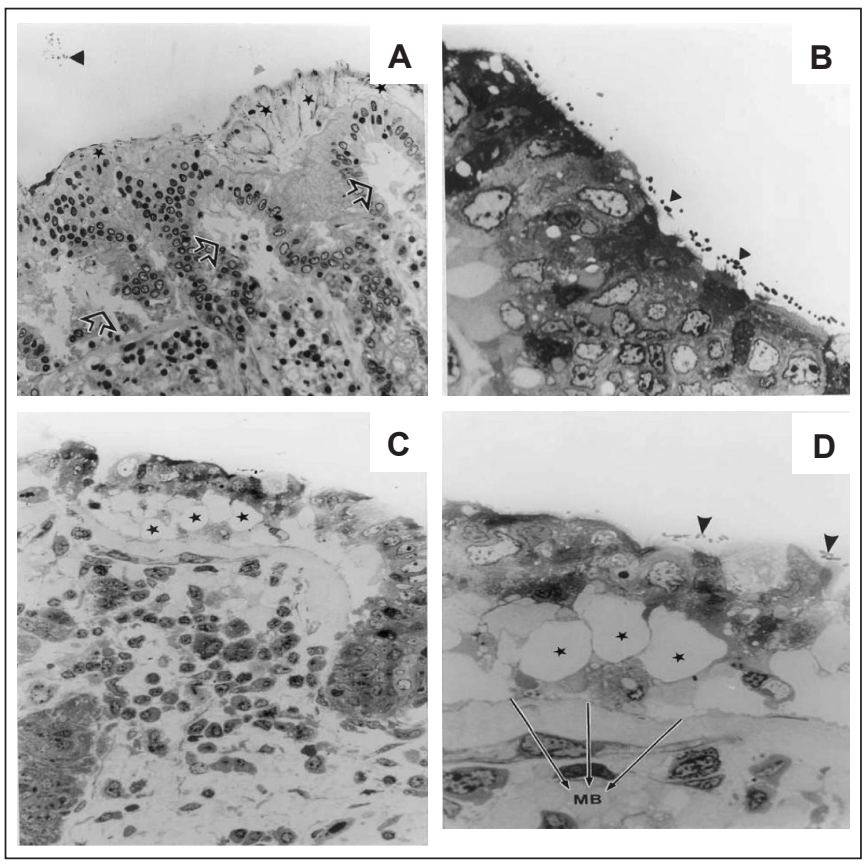

Figura 2 - Microscopia óptica de cólon infectado por EAEC. A e B - Cortes de fragmento intestinal mostrando superfície epitelial recoberta por espessa camada de muco $\left(^{*}\right)$ e grumos de bactérias evidenciados sobre a superfície epitelial $(\triangleright)$. Em $\Rightarrow$, notam-se áreas em que o epitélio encontra-se despregado do córion. C e D - Cortes semifinos demonstrando áreas de vacuolização na região basal dos enterócitos $\left(^{*}\right)$. Em D, MB demonstra a membrana basal preservada, * evidenciam vacúolos na região basal dos enterócitos e $>$ apontam aglomerados bacterianos próximos à superfície epitelial. A(210X); B(1050X); C(420X); D(1050X). apresentou-se despregado do córion em algumas regiões. Foram observados agregados bacterianos próximos às microvilosidades da superfície epitelial arrancada e nas áreas destruídas do tecido.

A análise da mucosa ileal infectada com a cepa 171-1 revelou regiões em que esboços de vilosidades apresentaram epitélio totalmente arrancado ou destruído (Figura 3). Restos de criptas foram observados (Figura 3A). As bactérias foram documentadas em agregados típicos e em algumas regiões em aparente invasão secundária (Figura 3D).

A cepa 101-1 provocou alterações idênticas às demonstradas para as outras cepas investigadas (71-1 e 171-1), em ambas as regiões estudadas.

\section{Discussão}

A infecção causada pelas cepas de EAEC representa uma causa importante de diarreia em países em desenvolvimento ${ }^{(20)}$. Recentemente, no Brasil, EAEC foi identificada como o principal agente causador de diarreia em crianças menores

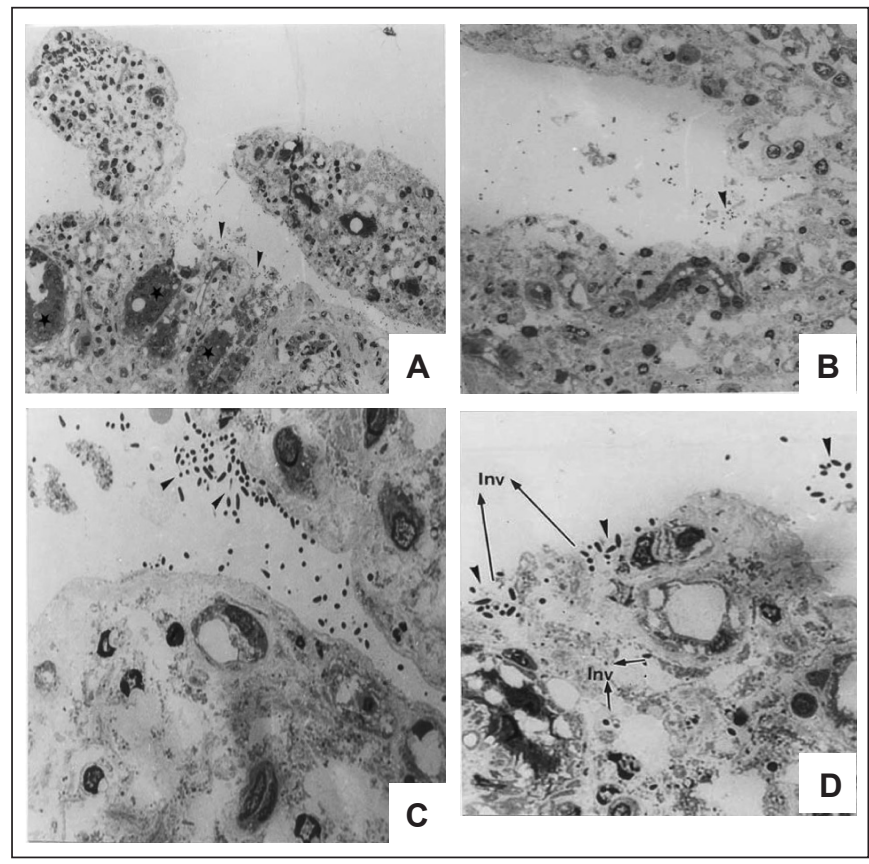

Figura 3 - Microscopia de luz de cortes semifinos de íleo infectado com a cepa 171-1. A, B, C e D - Regiões em que o epitélio de revestimento parece ter sido arrancado ou destruído, onde somente são envidenciados o córion desagregado e os restos de criptas $(\rightarrow)$. Notam-se bactérias em padrão AA típico em meio a restos celulares ( ) . D - Invasão secundária, a destruição tecidual é demonstrada (Inv). A(210X); B(420X); $\mathrm{C}(1050 \mathrm{X})$; D(1056X). 
de cinco anos de idade ${ }^{(21)}$. Nos Estados Unidos da América, EAEC também é descrita como um patógeno comum em crianças com diarreia ${ }^{(22)}$.

Sabe-se que alterações no intestino delgado explicam o prolongamento do processo diarreico ${ }^{(3)}$. Existem evidências de que esses micro-organismos podem colonizar o intestino delgado e a mucosa colônica, mas são encontradas variações entre as diferentes cepas ${ }^{(12,13)}$. A análise desta bactéria usando experimentos in vivo com modelos animais ${ }^{(23)}$ e cultura de orgão in vitro com enterócitos isolados e linhas celulares, tais como T84, Caco2, HT29, HeLa e HEp-2 ${ }^{(24)}$ e com fragmentos intestinais ${ }^{(12,13)}$, mostram uma explicação plausível para a tendência que essas bactérias têm de levar à persistência do processo diarreico. No entanto, os mecanismos envolvidos no dano provocado por elas ainda não estão totalmente esclarecidos.

Alguns estudos que avaliaram a interação de cepas de EAEC com o intestino humano, utilizando fragmentos intestinais de crianças e de adultos ${ }^{(25)}$, não observaram diferenças quanto ao grau de aderência. As três cepas avaliadas no presente estudo colonizaram o intestino delgado e o grosso, sendo que importantes alterações citotóxicas foram observadas em ambas as regiões. As alterações descritas na mucosa ileal poderiam justificar o prolongamento do processo diarreico. Existem várias hipóteses para explicar a perpetuação do dano à mucosa intestinal. In vivo, acredita-se que a má absorção dos nutrientes e a presença de antígenos microbianos possam estimular uma resposta imune que mantenha o dano à mucosa ${ }^{(7)}$. Por outro lado, a ausência de mecanismos de defesa nos procedimentos in vitro poderia ser um fator permissivo às alterações citotóxicas.

Nesta avaliação, as bactérias formaram agregados típicos em "pilha de tijolos" nas duas regiões estudadas. Foi confirmada a afinidade destes agentes às regiões do trato digestivo ricas em muco. Existiu liberação significativa de muco nos fragmentos de íleo e de cólon infectados por estes agentes. Os fragmentos intestinais avaliados mostraram destruição total ou parcial das vilosidades, vacuolização do citoplasma basal dos enterócitos, destacamento do epitélio e desarranjo da estrutura tecidual com perda de células epiteliais. Em algumas áreas, houve destruição epitelial total com ausência de microvilosidades. Essas lesões confirmaram os resultados de Vial et al, os quais, em estudo com alças intestinais de ratos e coelhos, demonstraram significantes áreas de destruição tecidual, sugerindo efeitos citotóxicos mais importantes no intestino delgado distal do que no proximal ${ }^{(26)}$. Hicks et al, mostraram cepas de EAEC interagindo com mucosas jejunal, ileal e colônicas ${ }^{(13)}$. Resultados similares foram encontrados por Nataro et al, que estudaram a cepa protótipo $042 \mathrm{em}$ células T84. Estes autores demonstraram que as células infectadas por esta cepa apresentaram marcados efeitos tóxicos, principalmente nas áreas onde a bactéria encontrava-se $\operatorname{aderida}^{(27)}$.

No cólon, foram observadas alterações morfológicas que justificariam a presença de muco e sangue nas fezes de pacientes com diarreia persistente infectados por EAEC. Pela ML, para todas as cepas avaliadas, foram demonstradas bactérias agregadas em "pilha de tijolos" na superfície epitelial, em meio a células inflamatórias e epiteliais (Figuras 2A, 2B e 2C). Nas regiões que se encontravam próximas ao epitélio, foi documentada grande quantidade de células caliciformes com áreas de lise, destruição e extrusão celular e áreas onde as bactérias apareceram mais próximas das microvilosidades que se mostraram alteradas. Em grande parte do tecido, no entanto, foi vista a bordadura estriada preservada. Nos fragmentos de íleo contaminados pela cepa 171-1, demonstrou-se destruição da superfície epitelial (sugestiva de ação citotóxica). A cepa 171-1 invadiu o tecido que se apresentou totalmente desagregado e desprovido de epitélio. No íleo, a cepa 042 , com os mesmos períodos de experimento (seis horas de incubação), levou a alterações aparentemente menos intensas, mas também significativas. Pela ML, foram demonstradas áreas de despregamento e arrancamento do epitélio. As lesões observadas poderiam ser devido a artefatos de técnica, mas não foram observadas nos controles. Acredita-se que as manifestações clínicas na diarreia por EAEC irão variar de indivíduo para indivíduo, dependendo da composição genética do hospedeiro. A distribuição genotípica da Interleucina 8 (IL8) em pacientes sintomáticos e assintomáticos está sendo estudada, e sugere-se que estas diferenças possam definir populações com maior ou menor suscetibilidade à infecção pelas EAEC ${ }^{(28)}$.

Em grande parte do tecido, foi vista a bordadura estriada preservada. Como já notado, as cepas de EAEC têm maior afinidade pelas regiões ricas em muco ${ }^{(29)}$. Houve aumento na produção de muco em ambas as regiões avaliadas em relação aos fragmentos controle.

No íleo, a presença de bactérias dentro das células poderia provocar maior exposição às toxinas ou a outras substâncias que causam lesões e, consequentemente, má absorção de nutrientes, favorecendo a penetração de antígenos bacterianos e alimentares. Estes podem estimular respostas imunes que perpetuam a lesão à mucosa e consequentemente a persistência da diarreia. 
Os dados disponíveis não permitem um completo entendimento da patogênese das EAEC, mas várias hipóteses são sugeridas. Existe um modelo proposto para a patogênese das EAEC, com três estágios, a saber:

- Inicialmente, ocorreria a adesão da bactéria à mucosa intestinal e/ou à camada de muco. As fímbrias seriam os principais candidatos a facilitadores desta colonização inicial.

- Haveria uma produção aumentada de muco, levando à formação de um biofilme, no qual as bactérias ficariam aderidas. A camada de muco poderia ser responsável pela colonização persistente da bactéria e talvez pela má absorção de nutrientes.

- Haveria a produção de citotoxinas, que provocariam danos às células intestinais, causando uma resposta inflamatória local com lesões citotóxicas da mucosa e secreção intestinal. Existe também a possibilidade de que hospedeiros desnutridos sejam particularmente prejudicados em sua capacidade de recuperação dos danos causados pela bactéria e, por isso, mais predispostos ao prolongamento do processo diarreico ${ }^{(1)}$.

\section{Referências bibliográficas}

1. Bhutta ZA. Persistent diarrhea in developing countries. Annales Nestlé 2006;64:39-48.

2. Mathers CD, Bernard C, Iburg KM, Inoue M, Fat DM, Shibuya K et al. Global burden of disease in 2002: data sources, methods and results. Geneva: World Health Organization; 2003.

3. Bhutta ZA, Ghishan F, Lindley K, Memon IA, Mittal S, Rhoads JM et al. Persistent and chronic diarrhea and malabsorption: Working Group report of the second World Congress of Pediatric Gastroenterology, Hepatology, and Nutrition. J Pediatr Gastroenterol Nutr 2004;39(Suppl 2):S711-6.

4. Islam D, Bandholtz L, Nilsson J, Wigzell H, Christensson B, Agerberth B et al. Downregulation of bactericidal peptides in enteric infections: a novel immune escape mechanism with bacterial DNA as a potential regulator. Nat Med 2001;180-7.

5. Binder HJ. Causes of chronic diarrhea. N Engl J Med 2006;355:236-9.

6. Baqui AH, Sack RB, Black RE, Haider K, Hossain A, Alim AR et al. Enteropathogens associated with acute and persistent diarrhea in Bangladeshi children less than 5 years of age. J Infect Dis 1992;166:792-6.

7. Black RE. Persistent diarrhea in children of developing countries. Pediatr Infect Dis J 1993;12:751-61.

8. Cravioto A, Tello A, Navarro A, Ruiz J, Villafán H, Uribe F et al. Association of Escherichia coli HEp-2 adherence patterns with type and duration of diarrhoea. Lancet 1991;337:262-4.

9. Nataro JP, Kaper JB, Robins-Browne R, Prado V, Vial P, Levine MM. Patterns of adherence of diarrheagenic Escherichia coli to HEp-2 cells. Pediatr Infect Dis J 1987;6:829-31.

10. Nataro JP, Deng Y, Cookson S, Cravioto A, Savarino SJ, Guers LD et al. Heterogeneity of enteroaggregative Escherichia coli virulence demonstrated in volunteers. J Infect Dis 1995;171:465-8.
Os distúrbios gastrintestinais provocados pelas EAEC parecem ocorrer por uma complexa interação entre o hospedeiro e o patógeno, incluindo a suscetibilidade genética do hospedeiro, a heterogeineidade dos fatores de virulência das EAEC e a quantidade de bactérias envolvidas na infecção.

Em conclusão, este estudo, que examinou a interação de três cepas de EAEC com a mucosa intestinal humana, confirmou que esses enteropatógenos são capazes de colonizar o intestino delgado e o grosso. Tais cepas bacterianas provocam alterações no epitélio absortivo do intestino delgado, podendo resultar na perpetuação do processo diarreico. Na mucosa colônica, as lesões inflamatórias descritas explicariam a colite mostrada em algumas crianças infectadas por $\mathrm{EAEC}^{(30)}$.

\section{Agradecimentos}

Este trabalho foi executado com o auxílio financeiro do Conselho Nacional de Desenvolvimento Científico e Tecnológico $(\mathrm{CNPq})$.

11. Elias WP, Uber AP, Tomita SK, Trabulsi LR, Gomes TA. Combinations of putative virulence markers in typical and variant enteroaggregative Escherichia coli strains from children with and without diarrhoea. Epidemiol Infect 2002;129:49-55.

12. Hicks S, Candy DC, Philips AD. Adhesion of enteroaggregative Escherichia coli to formalin-fixed intestinal and ureteric epithelia from children. J Med Microbiol 1996;44:362-71.

13. Hicks S, Candy DC, Philips AD. Adhesion of enteroaggregative Escherichia coli to pediatric intestinal mucosa in vitro. Infect Immun 1996;64:4751-60.

14. Sainz T, Perez J, Fresan MC, Flores V, Jimenez L, Hernandez U et al. Histological alterations and immune response induced by Pet toxin during colonization with enteroaggregative Escherichia coli (EAEC) in a mouse model infection. J Microbiol 2002;40:91-7.

15. Nataro JP. Enteroaggregative Escherichia coli pathogenesis. Curr Opin Gastroenterol 2005;21:4-8.

16. Baudry B, Savarino SJ, Vial P, Kaper JB, Levine MM. A sensitive and specific DNA probe to identify enteroaggregative Escherichia coli, a recently discovered diarrheal pathogen. J Infect Dis 1990;161:1249-51.

17. Ewing WH. Edwards and Ewing's identification of Enterobacteriaceae. $4^{\text {th }}$ ed. New York: Elsevier; 1986.

18. Knutton S, Lloyd DR, McNeish AS. Adhesion of enteropathogenic Escherichia coli to human intestinal enterocytes and cultured human intestinal mucosa. Infect Immun 1987;55:69-77.

19. Embaye H, Batt RM, Saunders JR, Getty B, Hart CA. Interaction of enteropathogenic Escherichia coli 0111 with rabbit intestinal mucosa in vitro. Gastroenterology 1989;96:1079-86.

20. Gioppo NM, Elias Jr WP, Vidotto MC, Linhares RE, Saridakis HO, Gomes TA et al. Prevalence of HEp-2 cell-adherent Escherichia coli and characterization 
of enteroaggregative Escherichia coli and chain-like adherent Escherichia coli isolated from children with and without diarrhoea, in Londrina, Brazil. FEMS Microbiol Lett 2000;190:293-8.

21. Araujo JM, Tabarelli GF, Aranda KR, Fabbricotti SH, Fagundes-Neto U, Mendes $\mathrm{CM}$ et al. Typical enteroaggregative and atypical enteropathogenic types Escherichia coli are the most prevalent diarrhea-associated pathotypes among Brazilian children. J Clin Microbiol 2007;45:3396-9.

22. Flores J, Okhuysen PC. Enteroaggregative Escherichia coli infection. Curr Opin Gastroenterol 2009;25:8-11.

23. Tickoo SK, Bhan MK, Srivastava R, Dass BK, Shariff M, Saini S et al. Intestinal colonization \& production of diarrhoea by enteroadherent-aggregative Escherichia coli. Indian J Med Res 1992;95:278-83.

24. Abe CM, Knutton S, Pedroso MZ, Freymüller E, Gomes TA. An enteroaggregative Escherichia coli strain of serotype O111: H12 damages and invades cultured T84 cells and human colonic mucosa. FEMS Microbiol Lett 2001;203:199-205.

25. Yamamoto T, Koyama Y, Matsumoto M, Sonoda E, Nakayama S, Uchimura $\mathrm{M}$ et al. Localized, aggregative and diffuse adherence to HeLa cells, plastic and human small intestines by Escherichia coli isolated from patients with diarrhea. J Infect Dis 1992;166:1295-310.

26. Vial PA, Robins-Browne R, Lior H, Prado V, Kaper JB, Nataro JP et al. Characterization of enteroadherent-aggregative Escherichia coli, a putative agent of diarrheal disease. J Infect Dis 1988;158:70-9.

27. Nataro JP, Hicks S, Phillips AD, Vial PA, Sears CL. T84 cells in culture as a model for of enteroaggregative Escherichia coli pathogenesis. Infect Immun 1996;64:4761-8.

28. Jiang ZD, Okhuysen PC, Guo DC, He R, King TM, DuPont HL et al. Genetic susceptibility to enteroaggregative Escherichia coli diarrhea: polymorphism in the interleukin-8 promotor region. J Infect Dis 2003;188:506-11.

29. Wanke CA, Cronan S, Goss C, Chadee K, Guerrant RL. Characterization of binding of Escherichia coli strains which are enteropathogens to small-bowell mucin. Infect Immun 1990;58:794-800.

30. Regua-Mangia AH, Gomes TA, Vieira MA, Andrade JR, Irino K, Teixeira LM. Frequency and characteristics of diarrhoeagenic Escherichia coli strains isolated from children with and without diarrhoea in Rio de Janeiro, Brazil. J Infect 2004;48:161-7. 